\title{
Efficacy of Topical Heparin in Prevention of Superficial Thrombophlebitis before Peripheral Venous Cannulation
}

\author{
Sinjini Agarwal ${ }^{1}$, Neeta Chaudhary Verma ${ }^{2}$, Amol Singam ${ }^{3}$ \\ ${ }^{1}$ Department of Anaesthesia, JNMC, DMIMS, Wardha, Maharashtra, India. ${ }^{2}$ Department of Anaesthesia, JNMC, DMIMS, \\ Wardha, Maharashtra, India. ${ }^{3}$ Department of Anaesthesia, JNMC, DMIMS, Wardha, Maharashtra, India.
}

\section{ABSTRACT}

\section{BACKGROUND}

Thrombophlebitis can be very commonly associated with peripheral venous cannulation. Many a times, thrombophlebitis may go undiagnosed. With serious complications and uncertainty of the treatment, it is always better to prevent its development. Prophylactic topical heparin application can significantly reduce the incidence of thrombophlebitis and also the complications related like deep venous thrombosis and pulmonary embolism which increase the hospital stay. Thus, this study was conducted to evaluate the efficacy of topical heparin in prevention of development of superficial thrombophlebitis.

\section{METHODS}

150 patients in the age group of 20 - 60 years, were randomly allocated to group $\mathrm{H}$ (Heparin), group C (Control), with 75 patients in each group. Group C received placebo (normal saline) and group $\mathrm{H}$ received topical heparin QPS before the insertion of the cannula on the dorsum of the upper limb and were observed at an interval of 8 hours until 72 hours using Visual Infusion Phlebitis Scale.

\section{RESULTS}

At the end of 72 hours, score of 0 , I, II, and III was observed in $5.33 \%, 44.00 \%$, $29.33 \%$ and $21.33 \%$ patients, respectively, in Group C; whereas score of 0, I, and II was observed in $60 \%, 25.33 \%$, and $14.67 \%$ patients, respectively in Group H (P = 0.0001). In Group C, score up to III was observed, whereas maximum score was II in Group $\mathrm{H}$ and that too at $72 \mathrm{~h}$ in only $14.67 \%$ of patients which proves the efficacy of topical QPS of heparin [Table 2].

\section{CONCLUSIONS}

Prophylactic topical application of QPS heparin was effective in preventing development of superficial thrombophlebitis.

\section{KEY WORDS}

Superficial Thrombophlebitis, Peripheral Venous Cannulation, Quick Penetrating Solution, Heparin
Corresponding Author: Neeta Chaudhary Verma, Department of Anaesthesia, AVBRH, JNMC, DMIMS, Sawangi, Wardha-442001, Maharashtra, India. E-mail: neetachaudhary1234@gmail.com

DOI: $10.14260 / \mathrm{jemds} / 2020 / 381$

Financial or Other Competing Interests: None.

How to Cite This Article:

Agarwal S, Verma NC, Singam A. Efficacy of topical heparin in prevention of superficial thrombophlebitis before peripheral venous cannulation. J. Evolution Med. Dent. Sci. 2020;9(23):1734-1738, $10.14260 /$ jemds $/ 2020 / 381$

Submission 11-04-2020,

Peer Review 15-05-2020,

Acceptance 21-05-2020,

Published 08-06-2020.
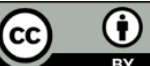


\section{BACKGROUND}

Intravenous cannulation is one of the most commonly performed procedures in a hospital setting1. Superficial thrombophlebitis, defined as an acute inflammation of superficial veins due to presence of a blood clot within the veins, is one of the most common complications of peripheral intravenous cannulation. ${ }^{2}$ Almost, about $70 \%$ of the patients admitted in a hospital, undergoing any type of major or minor surgery, require insertion of a peripheral cannula for the purpose of administering drugs, fluids, etc.; with upper limb being the most common site.

The incidence of superficial thrombophlebitis is around $5 \%-70 \%$ in hospitalized patients. ${ }^{3-4}$ Intravenous catheter, introduced in a vein acts as a foreign body, which leads to endothelial damage. Endothelial damage is one of the components of Virchow's triad of thrombosis namely- stasis of blood flow, endothelial damage and hypercoagulability. Phlebitis is induced by the inflammation of the tunica intima of superficial veins. Factors leading to this inflammation can be mechanical, chemical and infective. ${ }^{5}$

\section{Mechanical Phlebitis}

If the inserted cannula moves within the vein, it causes friction. Friction leads to inflammation which ultimately leads to thrombophlebitis. ${ }^{6}$ Size of the cannula also has an important role to play here. ${ }^{7}$ Moreover if the vein is not selected accordingly, that is away from the joint or a venous valve, it might lead to thrombophlebitis. ${ }^{8}$ Additionally, cannula must be secured well to reduce its movement in the vein to prevent mechanical thrombophlebitis.

\section{Chemical Phlebitis}

$\mathrm{Ph}$ and osmolarity of the drugs and fluids infused through the cannula has a significant effect on the incidence of phlebitis. ${ }^{9}$ Antibiotics, which are routinely used during the surgeries in the operation theatres, have low $\mathrm{pH}$ and thus increase the rates of chemical phlebitis. Bringing the $\mathrm{pH}$ or osmolarity nearer to that of the blood can help avoid chemical phlebitis. Hypertonic fluids also, in comparison to isotonic fluids, increase the rates of phlebitis by inducing inflammatory responses.

\section{Infective Phlebitis}

While inserting a cannula if adequate hygiene measures are not followed, can lead to infective phlebitis. Poor hand hygiene or poor skin cleansing methods before inserting a peripheral venous catheter, increase the incidences of infective phlebitis. ${ }^{10}$ Once infective phlebitis develops, it may develop into systemic sepsis. The most common symptoms of thrombophlebitis are redness, swelling and palpable venous cords. Any kind of discomfort or pain felt by the patient during drug injection may indicate superficial thrombophlebitis.

Prevention of phlebitis is important because, its development leads to acute inflammation causing redness, swelling, increased temperature in the surrounding area and also palpable venous cords ${ }^{3}$. If not treated in time, it may lead to deep venous thrombophlebitis which might lead to sudden pulmonary embolism increasing the cost and hospital stay.

Thus, to prevent the serious complications associated, prophylactic treatment must be administered as prevention is always better than cure. Topical heparin solutions are used for the prevention and the treatment of intravenous catheter induced superficial venous thrombophlebitis. Novel topical quick penetrating solution of heparin sodium $(1000 \mathrm{IU} / \mathrm{ml})$ developed by Troikaa pharmaceuticals limited helps heparin to penetrate the skin effectively without any systemic absorption or risk of bleeding. ${ }^{11}$ QPS contains non aqueous and non-volatile solvents with added permeability enhancers to increase the penetration of the heparin across the skin.

We conducted this study with the objective of studying clinical efficacy of topical heparin solution QPS (1000 IU/ml) in comparison to placebo (normal saline) in preventing the incidence of phlebitis, before the insertion of peripheral venous cannula.

\section{METHODS}

The present study is a prospective, interventional study, conducted after getting clearance from Institutional Research and Committee and written consent. A total of 150 patients, posted in operation theatre or intensive care unit requiring a venous cannulation for $\geq 72$ hours in the upper limb (preferably) between May 2019 and November 2019, belonging to the American Society of Anaesthesiologists' (ASA) physical status(I and II), aged 20-60 years of either gender were selected for the study. Patients were divided into two groups using a computer-generated random number table. Group $\mathrm{H}$ (heparin group) received topical heparin $(1000 \mathrm{IU} / \mathrm{ml}) 8$ hourly and Group C patients received normal saline 8 hourly. Patients in the OT with a good peripheral vein on the forearm, away from the joints were selected preferably dorsum of the hand.

The selected site was cleaned with surgical spirit and then after the spirit dried, topical heparin $(1000 \mathrm{IU} / \mathrm{ml})$ (Phlebotroy, QPS, Troikaa Pharmaceuticals) 10 drops were applied to the site along the length of the cannula and surroundings. ${ }^{12}$ This time was marked as 0 hour. Adequate care was taken to avoid any contact of treated area by doctors, staff nurses or other objects for 15-20 minutes after application. After that, an 18 Gauge Cannula (B Braun Vasofix) was inserted using aseptic precautions. Each $\mathrm{ml}$ delivered approximately 30-40 drops of heparin. The maximum single dose of 34 drops i.e. 1000 IU was not exceeded. Every 8 hours, the same site was examined and graded using Visual Infusion Phlebitis Score, ${ }^{5}$ and again 10 drops were applied, and the site was covered with adhesive tape for next 8 hours. Any score of 1 or greater was considered phlebitis. This regime was followed for 72 hours. Any adverse effect if present was noted. Patients with known hypersensitivity to heparin, coagulation disorders, sepsis, deep-vein thrombosis, carcinoma, diabetes mellitus, and contraindication to heparin were excluded from the study. Also, patients on anticoagulants, pregnant and lactating patients, and those not willing to participate in the study were excluded. 


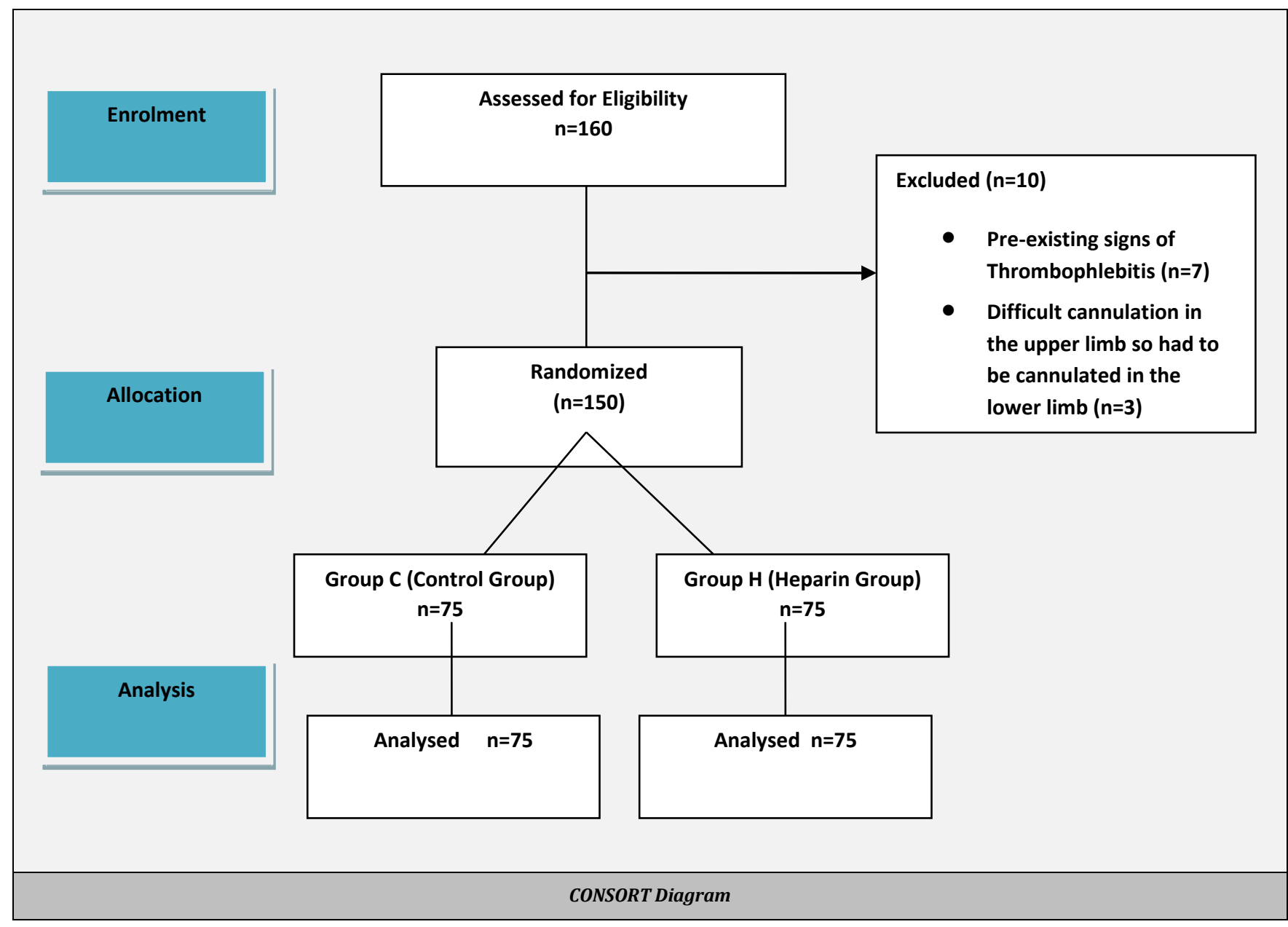

\begin{tabular}{|c|c|c|c|}
\hline $\begin{array}{c}\text { Grade of } \\
\text { Phlebitis } \\
0\end{array}$ & $\begin{array}{c}\text { Appearance of } \\
\text { Cannulation Site } \\
\text { Appears Healthy }\end{array}$ & $\begin{array}{l}\text { Stage and Action } \\
\text { Required } \\
\text { No Signs of } \\
\text { Phlebitis }\end{array}$ & Remarks \\
\hline I & $\begin{array}{l}\text { One of the following is evident: } \\
\text { - } \quad \text { Slight pain near IV site } \\
\text { Slight redness near IV site }\end{array}$ & $\begin{array}{l}\text { Possibly first sign of } \\
\text { phlebitis }\end{array}$ & $\begin{array}{l}\text { Observe the } \\
\text { cannula }\end{array}$ \\
\hline II & $\begin{array}{l}\text { Two of the following are evident: } \\
\text { - } \quad \text { Pain at IV site } \\
\text { Erythema } \\
\text { - } \quad \text { Swelling }\end{array}$ & $\begin{array}{l}\text { Early stage of } \\
\text { phlebitis }\end{array}$ & $\begin{array}{l}\text { Resite the } \\
\text { cannula }\end{array}$ \\
\hline III & $\begin{array}{l}\text { All of the following are evident: } \\
\text { 1. Pain along the path of the } \\
\text { cannula } \\
\text { 2. Erythema } \\
\text { 3. Induration }\end{array}$ & $\begin{array}{l}\text { Medium stage of } \\
\text { phlebitis }\end{array}$ & $\begin{array}{l}\text { Resite the } \\
\text { cannula. } \\
\text { Consider } \\
\text { treatment. }\end{array}$ \\
\hline IV & $\begin{array}{l}\text { All of the following signs are evident } \\
\text { and extensive: } \\
\text { - } \quad \text { Pain along the path of the } \\
\text { cannula } \\
\text { - } \quad \text { Erythema } \\
\text { - Induration } \\
\text { - Palpable venous cord }\end{array}$ & $\begin{array}{l}\text { Advanced stage of } \\
\text { phlebitis or start of } \\
\text { thrombophlebitis }\end{array}$ & $\begin{array}{l}\text { Resite the } \\
\text { cannula. } \\
\text { Consider } \\
\text { treatment }\end{array}$ \\
\hline $\mathrm{V}$ & $\begin{array}{l}\text { All of the following signs are evident } \\
\text { and extensive: } \\
\text { - } \quad \text { Pain along the path of the } \\
\text { cannula } \\
\text { - } \quad \text { Erythema } \\
\text { - Induration } \\
\text { - } \quad \text { Palpable venous cord } \\
\text { - } \quad \text { Pyrexia }\end{array}$ & $\begin{array}{l}\text { Late stage of } \\
\text { phlebitis }\end{array}$ & $\begin{array}{l}\text { Resite the } \\
\text { cannula. } \\
\text { Initiate } \\
\text { treatment. }\end{array}$ \\
\hline \multicolumn{4}{|c|}{ Table 1. Visual Infusion Phlebitis Score ${ }^{5}$} \\
\hline
\end{tabular}

\section{Sample Size Calculation}

150 patients are required to have a 95\% chance of detecting, as significant at the $1 \%$ level, a decrease in the primary outcome measure from $62.9 \%$ in the experimental group to $30.3 \%$ in the control group.

\section{Calculation Based on the Formula}

$$
n=\frac{\mathrm{f}(\alpha / 2, \beta) \times[\mathrm{p} 1 \times(100-\mathrm{p} 1)+\mathrm{p} 2 \times(100-\mathrm{p} 2)]}{(\mathrm{p} 2-\mathrm{p} 1)^{2}}
$$

Where, p1 and p2 are the percent 'success' in the control and experimental group respectively.

\section{Statistical Analysis}

All characteristics were summarized descriptively. For continuous variables, the summary statistics of $\mathrm{N}$, mean, standard deviation (SD) were used. For categorical data, the number and percentage were used in the data summaries and data were analyzed by Chi square test for association, and diagrammatic presentation. If the $p$-value was $<0.05$, then the results were considered to be statistically significant otherwise it was considered as not statistically significant. Data were analyzed using SPSS software v.23.0. And Microsoft office 2007.

\section{RESULTS}

A total of 150 patients were enrolled for the study. The demographic data of both the groups were comparable in age, sex, ASA grading, size of cannula and duration of cannulation.

In Group C, at 8 hours, score of 0 and I was observed in $60 \%$ of patients and $40 \%$ of patients, respectively, whereas, all the $100 \%$ of patients had the score of 0 in Group $\mathrm{H}(\mathrm{p}$ 
$<0.0001$ ). At 16 hours, the score of 0 and I, was observed in $46.67 \%$ and $53.33 \%$ of patients, respectively, in Group C, whereas the score of 0 and 1 was observed in $90.67 \%$ and $9.33 \%$ of patients, respectively, in Group $\mathrm{H}(\mathrm{p}<0.0001)$. At 24 hours, the score of 0 , I and II was observed in 37.33\%,56.00\% and $6.67 \%$ of patients, respectively, in Group C, whereas score of 0 and I was observed in $86.67 \%$ and $13.33 \%$ of patients, respectively, in Group $\mathrm{H}(\mathrm{p}<0.0001)$. At 32 hours, the score of 0 , I and II was observed in $29.33 \%, 58.67 \%$ and $12 \%$ of patients, respectively, in Group C, whereas score of 0 and I was observed in $78.67 \%$ and $21.33 \%$ of patients, respectively, in Group $\mathrm{H}(\mathrm{p}<0.0001)$. At 48 hours, the score of 0 , I and II was observed in $20 \%, 60 \%$ and $20 \%$ of patients, respectively, in Group C, whereas score of 0 , I and II was observed in $68 \%, 24 \%$ and $8 \%$ of patients, respectively, in Group H ( $\mathrm{p}<0.0001)$. At the end of 72 hours, score of 0 , I, II, and III was observed in 5.33\%, 44.00\%,29.33\% and $21.33 \%$ patients, respectively, in Group C, whereas score of 0 , I, and II was observed in $60 \%, 25.33 \%$, and $14.67 \%$ patients, respectively, in Group H ( $\mathrm{p}=.0001)$. In Group C, score up to III was observed, whereas maximum score was II in Group $\mathrm{H}$ and that too at $72 \mathrm{~h}$ in only $14.67 \%$ of patients which proves the efficacy of topical QPS of heparin [table 2].

\begin{tabular}{|c|c|c|c|c|c|}
\hline Hours & $\begin{array}{l}\text { Grade of } \\
\text { Phlebitis }\end{array}$ & $\begin{array}{c}\text { Group } \\
\text { C } \\
\text { Percentage }\end{array}$ & $\begin{array}{c}\text { Group } \\
\text { H } \\
\text { Percentage }\end{array}$ & $\begin{array}{c}\text { Chi } \\
\text { Square }\end{array}$ & $\begin{array}{c}P \\
\text { Value }\end{array}$ \\
\hline 0 Hour & Grade 0 & 100 & 100 & & \\
\hline 8 Hours & $\begin{array}{l}\text { Grade } 0 \\
\text { Grade1 }\end{array}$ & $\begin{array}{l}60 \\
40\end{array}$ & 100 & 37.25 & $<0.0001$ \\
\hline 16 Hours & $\begin{array}{l}\text { Grade } 0 \\
\text { Grade } 1\end{array}$ & $\begin{array}{l}46.67 \\
53.33\end{array}$ & $\begin{array}{c}90.67 \\
9.33\end{array}$ & 33.17 & $<0.0001$ \\
\hline 24 Hours & $\begin{array}{l}\text { Grade } 0 \\
\text { Grade 1 } \\
\text { Grade } 2\end{array}$ & $\begin{array}{c}37.33 \\
56.00 \\
6.67\end{array}$ & $\begin{array}{c}86.67 \\
13.33 \\
0.00\end{array}$ & 39.00 & $<0.0001$ \\
\hline 32 Hours & $\begin{array}{l}\text { Grade 0 } \\
\text { Grade 1 } \\
\text { Grade } 2\end{array}$ & $\begin{array}{l}29.33 \\
58.67 \\
12.00\end{array}$ & $\begin{array}{c}78.67 \\
21.33 \\
0.00\end{array}$ & 37.02 & $<0.0001$ \\
\hline 48 Hours & $\begin{array}{l}\text { Grade } 0 \\
\text { Grade 1 } \\
\text { Grade } 2\end{array}$ & $\begin{array}{l}20.00 \\
60.00 \\
20.00\end{array}$ & $\begin{array}{c}68.00 \\
24.00 \\
8.00\end{array}$ & 34.83 & $<0.0001$ \\
\hline 72 Hours & $\begin{array}{l}\text { Grade } 0 \\
\text { Grade 1 } \\
\text { Grade 2 } \\
\text { Grade 3 }\end{array}$ & $\begin{array}{c}5.33 \\
44.00 \\
29.33 \\
21.33 \\
\end{array}$ & $\begin{array}{c}60.00 \\
25.33 \\
14.67 \\
0.00 \\
\end{array}$ & 36.89 & $<0.0001$ \\
\hline & Table & servatic & ind Resul & & \\
\hline
\end{tabular}

\section{DISCUSSION}

Intravenous cannulation is one of the most common component of hospital management to administer drugs, fluids, blood, other infusates etc. and superficial thrombophlebitis is one of its most common complications. Although superficial thrombophlebitis is benign and selflimiting $^{2}$, can lead to deep venous thrombophlebitis and pulmonary embolism if not prevented.13 The duration of cannulation, material, size, type of infusate used and existing superficial skin infections are important risk factors. ${ }^{14}$

Duration of the catheter in the vein plays an important role in the development of superficial thrombophlebitis. A catheter left in the vein for more than 72 hours, runs a higher risk of developing thrombophlebitis. More the duration of the cannula, more is the risk of thrombophlebitis. A cannula which has been inserted longer than 72 hours should be shifted to another site or replaced at the first instance, even though there are no signs of thrombophlebitis. A cannula should ideally be removed if no longer needed. In our study, we studied the incidences of thrombophlebitis that occurred within 72 hours and not beyond that. ${ }^{12}$

Incidences of thrombophlebitis get influenced by the location of the cannula also. Catheters placed near the joints, bony prominences or venous valves carry more risk of thrombophlebitis. Also, the catheters placed on the upper limb have lower rates of developing into thrombophlebitis than those placed on the lower limb.12 In our study, we studied the incidences of thrombophlebitis in catheters placed only on the dorsum of the upper limb. As, there are no specific treatment protocols ${ }^{15}$ it is best advised to initiate prophylactic treatment.

In our study, we administered topical heparin QPS before the insertion of the cannula and this proved to be effective in prevention of development of thrombophlebitis.

According to a previous study where no prophylaxis was administered, $50 \%$ patients were reported with thrombophlebitis, with grade I being $61 \%$ and grade II being $39 \% .{ }^{16}$ In our study, we observed that $60 \%$ had no thrombophlebitis while grade I of phlebitis was reported in only $25.3 \%$ and grade II in $14.7 \%$.

Similarly, in another study which evaluated the efficacy of topical QPS heparin in preventing thrombophlebitis. This study was conducted on a group of 200 patients with 100 in each control and heparin group. It was observed that at the end of 72 hours in control group maximum grade was grade IV while in heparin group only up to grade II was seen that too in 16 patients out of $100 .{ }^{17}$ The results of this study are comparable with our study.

Our study also agrees with yet another study which compared the efficacy of topical heparin QPS and diclofenac QPS for prevention of superficial thrombophlebitis. And, heparin QPS was observed to be $100 \%$ effective in the prevention of peripheral intravenous cannulation induced superficial thrombophlebitis proving diclofenac QPS inferior as $23 \%$ of patients developed grade I thrombophlebitis in this group. ${ }^{18}$

Also, as observed in another study, two thirds of the patients on whom QPS topical heparin was used, developed mild grade of thrombophlebitis only. Moderate and severe phlebitis were not very commonly noted because they took preventive measures by the application of topical heparin prophylactically and thus prevented development of advanced thrombophlebitis. ${ }^{12}$

The unique point in our study was that, that we used heparin QPS before the insertion of cannula. In all other studies it had been used after the insertion and before securing the cannula. We used VIP scale $^{5}$ to grade the phlebitis in our study. VIP scale developed by Jackson (1998) is a reliable tool for determining the time of removal the intravenous cannula ${ }^{19}$ and the Phlebitis scale by developed by INS (2006) ${ }^{20}$ are the two most commonly used scales. These scales help in the assessment of phlebitis and in the reduction of progression of phlebitis through early detection. $^{21}$ So, in this study, among the 150 patients observed, more no. of patients developed thrombophlebitis from the control group in comparison to heparin group, therefore proving that prophylactic topical application of heparin QPS before peripheral intravenous cannulation prevents the development of superficial thrombophlebitis thus keeping its incidence below $5 \% .10$ 
The low cost and easy application of QPS topical heparin solution without any adverse effects makes it an ideal prophylaxis in prevention of superficial thrombophlebitis. Because of these properties, it also saves the hassles of frequent changing of the I.V. cannulas, thus reducing the cost and hospital stay. ${ }^{1}$

\section{CONCLUSIONS}

In our study, we found that overall incidence of thrombophlebitis was $40 \%$ in the heparin group as compared to $95.6 \%$ in the control group. Thus, topical heparin is definitely effective in reducing the incidence rate of thrombophlebitis which is particularly significant in patients in whom IV cannulation is required for longer duration for administration of drugs. ${ }^{10}$

\section{REFERENCES}

[1] Babu AT, Sharmila V. Prophylactic topical heparin can prevent or postpone intravenous cannula induced superficial thrombophlebitis. Med Hypotheses 2010;74(5):857-8.

[2] Saini V, Samra T, Ahuja N, et al. A prospective randomized study to evaluate safety and efficacy of heparin topical solution $(1000 \mathrm{IU} / \mathrm{ml})$ compared to heparin topical gel $(200 \mathrm{IU} / \mathrm{g})$ in prevention of infusion-associated phlebitis. Indian J Pharmacol 2018;50(6):344-9.

[3] Jackson A. Infection control - a battle in vein: infusion phlebitis. Nurs Times 1998;94(4):68-71.

[4] Belcaro G, Cesarone MR, Dugall M, et al. Topical formulation of heparin is effective in reducing the symptoms of superficial venous thrombosis: a monocenter, observer-blind, placebo-controlled randomized study. Panminerva Med 2011;53(3 Suppl 1):3-11.

[5] Royal College of Nursing Standards for infusion therapy. London: RCN 2010. tinyurl.com/RCN-Infusion.

[6] Stokowski G, Steele D, Wilson D. The use of ultrasound to improve practice and reduce complication rates in peripherally inserted central catheter insertions: final report of investigation. Journal of Infusion Nursing 2009;32(3):145-55.

[7] Martinho RFS, Rodrigues AB. Occurrence of phlebitis in patients on intravenous amiodarone. Einstein (Sao Paulo) 2008;6(4):459-62.
[8] Macklin D. Phlebitis, a painful complication of peripheral IV catheterization that may be prevented. American Journal of Nursing 2003;103(2):55-60.

[9] Kohno E, Murase S, Matsuyama K, et al. Effects of corticosteroids on phlebitis induced by intravenous infusion of antineoplastic agents in rabbits. International Journal of Medical Sciences 2009;6(5):218-23.

[10] Uslusoy E, Mete S. Predisposing factors to phlebitis in patients with peripheral intravenous catheters: a descriptive study. J Am Acad Nurse Pract 2008;20(4):172-80.

[11] Vecchio C, Frisinghelli A. Topically applied heparins for the treatment of vascular disorders: a comprehensive review. Clin Drug Investig 2008;28(10):603-14.

[12] Beigh OA, Rahaman H. Efficacy of topical heparin in preventing the incidence of thrombophlebitis after peripheral intra venous cannulation. IOSR J Dent Med Sci (IOSR-JDMS) 2016;15(7):50-4.

[13] Kitchens CS. How I treat superficial vein thrombosis. Blood 2011;117(1):39-44.

[14] Frappe P, Buchmuller-Cordier A, Bertolett L, et al. Annual diagnosis rate of superficial-vein thrombosis of the lower limbs: the STEPH community-based study. J Thromb Haemost 2014;12(6):831-8.

[15] Cosmi B. Management of superficial vein thrombosis. J Thromb Haemost 2015;13(7):1175-83.

[16] Saji J, Korula SV, Mathew A, et al. The incidence of thrombophlebitis following the use of peripheral intravenous cannula in post-operative patients a prospective observational study. IOSR J Dent Med Sci 2015;14(6):1-4.

[17] Bansal T, Kumar P, Vashisht G. A study to evaluate the efficacy of topical quick penetrating solution of heparin in preventing thrombophlebitis. Indian Anaesth Forum 2019;20(2):95-8.

[18] Akhileshwar, Singh S. Comparison of heparin quick penetrating solution and diclofenac quick penetrating solution for the prevention of superficial thrombophlebitis caused by peripheral venous cannulation: a randomized double-blind study. Anesth Essays Res 2019;13(1):155-7.

[19] Gallant P, Schultz AA. Evaluation of a visual infusion phlebitis scale for determining appropriate discontinuation of peripheral intravenous catheters. J Infus Nurs 2006;29(6):338-45.

[20] Infusion Nurses Society. Infusion nursing standards of practice. J Infus Nurs 2006;29(1 Suppl):S1-92.

[21] Creed F, Spiers C. Care of the acutely ill adult: an essential guide for nurses. Oxford: Oxford University Press

2010 